\title{
Evaluación de diferentes péptidos de la región estructural del virus de la hepatitis $\mathbf{C}$
}

\author{
Ivonne Gómez, Milenen Hernández, Carlos Martínez, Marleby García, Antonio Melchor \\ Centro de Inmunoensayo, Ciudad de La Habana, Cuba
}

\begin{abstract}
Para el diagnóstico del virus de la hepatitis C, se utilizan ampliamente las pruebas de Elisa por su sensibilidad y especificidad. Gran parte de ellos se basa en el empleo de péptidos sintéticos. Una de las zonas más conservadas y de gran antigenicidad es la región estructural del virus. En este estudio, se sintetizaron siete péptidos de zonas informadas como altamente antigénicas de la región estructural del virus de la hepatitis C. Los péptidos sintetizados representan la región del núcleo del virus. Se realizó la evaluación y comparación de los resultados de los péptidos sintetizados, para lo cual se emplearon muestras positivaș $(n=72)$ y negativas $(n=42)$. Con los péptidos más cercanos a la región amino terminal, la reactividad fue alta, pero fue disminuyendo a medida que nos acercábamos a la región carboxilo terminal. Estos resultados coinciden con lo informado por otros autores.

Palabras clave: péptidos sintéticos, HCV core, UMELISA

\section{Evaluation of different peptides in hepatitis. $C$ virus structural region}

Elisa tests are widely used for the diagnosis of hepatitis $C$ virus infection because of their sensitivity and specificity. Most of the Elisas are based on the use of synthetic peptides. The structural region of the virus is one of the most preserved regions and it shows high immunogenicity. Seven highly immunogenic peptides from highly immunogenic areas in hepatitis $\mathrm{C}$ virus structural region were synthesized. Those peptides represent the structural region of the hepatitis $C$ virus. Results of synthesized peptides were tested and compared. Positive $(n=72)$ and negative $(n=42)$ samples were employed. Reactivity was high in peptides closest to the $\mathrm{N}$-terminus region and it decreased toward the C-terminus region. The results coincide with other authors' results.
\end{abstract}

Key words: synthetic peptides, HCV core, UMELISA

El virus de la hepatitis $\mathrm{C}(\mathrm{HCV})$ está compuesto por un genoma de ARN de cadena simple con sentido positivo de aproximadamente 9.500 nucleótidos ( 9,4 kilobases), que codifica para una poliproteína de alrededor de 3.000 aminoácidos, con elevado grado de heterogeneidad genética $(1,2)$. Puede fragmentarse en tres proteínas estructurales (C, E1 y E2/NS1) y seis no estructurales (NS2, NS3, NS4a, NS4b, NS5a y NS5b) (1).

La proteína estructural del núcleo (C) está altamente conservada y presenta una gran antigenicidad entre los diferentes aislamientos, de ahí la importancia de su incorporación en los

Correspondencia:

iqpeptidos@cie.sld.cu

Recibido: 12/04/00; aceptado: 02/02/01 ensayos diagnósticos para la detección de anticuerpos a este virus (3-6). Sin embargo, se ha observado que las zonas cercanas a la región amino terminal son las más antigénicas. A medida que nos alejamos de estas zonas hacia la región carboxilo terminal, la reactividad va disminuyendo (3-6).

En este trabajo se presentan los resultados comparativos de la evaluación de siete péptidos de diferentes regiones del núcleo. Todos los péptidos se sintetizaron de sitios altamente antigénicos.

\section{Materiales y métodos}

\section{Síntesis de péptidos}

Con el empleo de la predicción de los determinantes antigénicos de las proteínas (7), 
se sintetizaron siete péptidos representativos del virus de la hepatitis C. Los péptidos estaban comprendidos entre los aminoácidos 2-60 para Core1 (31 aminoácidos) y Core2 (20 aminoácidos); entre los aminoácidos 40-90, los péptidos Core3 (26 aminoácidos), Core4 (20 aminoácidos), Core5 (27 aminoácidos) y Core6 (20 aminoácidos), y entre los aminoácidos 100-130, el péptido Core7 (25 aminoácidos). Los péptidos se sintetizaron en fase sólida según el método descrito por Merrifield en 1963, siguiendo la estrategia Boc- en bolsas de polipropileno (Biotech. Instruments, USA) (8). Se utilizaron $100 \mathrm{mg}$ de la resina 4-metilbenciIhidrilamina (MBHA) (100-200 mesh, $1 \mathrm{mmol} / \mathrm{g}$, Bachem) (9) y el grupo alfa-amino de los aminoácidos protegidos con el grupo Boc(BACHEM, Suiza). Las reacciones de acoplamiento se realizaron por activación del grupo carboxilo de cada aminoácido con cantidades equivalentes de diisopropilcarbodimida (DIPCDI) 0,2 mol/L en diclorometano (DCM). La eficiencia del acoplamiento de los aminoácidos protegidos se verificó con ayuda del ensayo de ninhidrina. La protección temporal (Boc-) se eliminó con ácido trifluoracético al $37,5 \%$ en $\operatorname{DCM}(8,9)$. La desprotección final fue por el método low-high con ácido fluorhídrico (HF) puro para análisis (Fluka, Suiza) $(8,9)$. La extracción del péptido se hizo con ácido acético al $30 \%$ en agua destilada. El extracto final, diluido en agua, se liofilizó en una liofilizadora Edwards de tecnología inglesa de $9 \mathrm{~kg}$ de capacidad en el condensador.

\section{Caracterización de los péptidos sintéticos}

La determinación de la pureza de los péptidos sintéticos se realizó por el sistema HPLC (High Performance Liquid Chromatography) mediante cromatografía de fase reversa (RP-HPLC) (10), en la que se aplicaron $0,2 \mathrm{mg}$ de péptido (gradiente: 0-60\% B (33'); velocidad de flujo: 0,5 $\mathrm{mL} / \mathrm{min}$; velocidad del papel: $2 \mathrm{~mm} / \mathrm{min}$; sensibilidad: 0,1 AUFS y temperatura: $22^{\circ} \mathrm{C}$ ). En los cromatogramas se observó una señal principal que se correspondía con la máxima actividad de los péptidos en el UMELISA. La caracterización del péptido de mejores resultados se realizó mediante la espectrometría de masas MALDI-TOF (Matrix Assisted Laser Desorption of Ions Time- of Flight) (11) y el peso molecular coincidió con el peso teórico.

\section{Recubrimiento de la fase sólida}

Con cada uno de los péptidos por separado, se preparó una disolución a $2 \mathrm{mg} / \mathrm{ml}$ en carbonatobicarbonato, 0,05 mol/l, pH 9,6. Como fase sólida se emplearon placas de poliestireno irradiado (12) con capacidad para $30 \mathrm{ml}$ (placas UMELISA, Greiner labortechnik, Alemania), las que se recubrieron a $15 \mathrm{ml} /$ pocillo y se incubaron 4 horas a $37^{\circ} \mathrm{C}$. La placas se lavaron con una disolución amortiguadora de PBS-T ( $8 \mathrm{~g}$ de $\mathrm{NaCl} ; 1,215 \mathrm{~g}$ de $\mathrm{Na}_{2} \mathrm{HPO}_{4} \cdot 2 \mathrm{H}_{2} \mathrm{O} ; 0,2 \mathrm{~g}$ de $\mathrm{KH}_{2} \mathrm{PO}_{4} ; 0,2 \mathrm{~g}$ de $\mathrm{NaN}_{3}$; $0,5 \mathrm{~mL}$ de Tween-20, para un volumen de 1.000 $\mathrm{mL}$ de agua destilada y $\mathrm{pH}$ de $7,3-7,5) \mathrm{y}$, posteriormente, se bloquearon con una disolución de preservo (sacarosa al $5 \%$ y BSA al $1 \%$ en PBS-Tween), durante toda la noche a temperatura ambiente $\left(20-25^{\circ} \mathrm{C}\right)$. Se aspiró la disolución de preservo y la fase sólida se dejó secar a $37^{\circ} \mathrm{C}$ durante 2 horas. Las placas recubiertas se conservaron a $4{ }^{\circ} \mathrm{C}$, en una cubierta protectora, hasta el momento de su uso (1).

\section{Ensayo UMELISA}

Las muestras por evaluar se diluyeron 1:20 en suero de carnero al $5 \%$ en una disolución amortiguadora Tris- $\mathrm{HCl}$ ( $15 \mathrm{mmol} / \mathrm{l}$ de Tris; $\mathrm{pH} 7,8$ y $0,05 \%$ Tween-20) y se incubaron $30 \mathrm{~min}$ a $37^{\circ} \mathrm{C}$ en las placas de reacción. Se lavó tres veces con la disolución amortiguadora Tris- $\mathrm{HCl}$ para eliminar los componentes no fijados y se adicionó un conjugado anti-IgG humana en carnero, marcada con fosfatasa alcalina (Böehringer Mannheim $\mathrm{GmbH}$, Alemania), que se incubó durante 30 minutos a $37^{\circ} \mathrm{C}$. Se realizó un nuevo lavado en las mismas condiciones y se añadió, entonces, el sustrato fluorigénico 4-metilumbeliferilfosfato (Koch Light Ltd. Haverhill, Suffolk, England), el cual se incubó durante 30 minutos a temperatura ambiente (13). La fluorescencia emitida se midió en un fluorímetro de la serie SUMA ${ }^{\circledR}$ (PR-521, Centro de Inmunoensayo) (excitación a $365 \mathrm{~nm}$ y emisión a $450 \mathrm{~nm}$ ). En todos los experimentos, se incluyeron controles positivos y negativos, los ensayos se realizaron por cuadriplicado y las muestras se analizaron por duplicado. 


\section{Muestras}

Se analizaron muestras positivas de diferente procedencia $(n=72)$ confirmadas por el ensayo confirmatorio Deciscan HCV, y muestras negativas $(n=42)$.

\section{Parámetros de evaluación clínica}

Según estudios previos, se determinó como nivel de corte 0,3 . Se consideran positivas todas las muestras en las cuales (13):

$$
\begin{array}{ll}
\frac{R}{N c}>1 \quad \text { donde: } & \text { Nc: nivel de corte } \\
& \text { R: relación de corte } \\
\mathrm{R}=\frac{(\mathrm{Fm}-\mathrm{Xb})}{(\mathrm{Fmenor}-\mathrm{Xb})} \times 0,3 & \begin{array}{l}
\text { la muestra } \\
\text { lat media del blanco }
\end{array} \\
& \begin{array}{l}
\text { Fmenor: fluorescencia } \\
\text { menor del positivo. }
\end{array}
\end{array}
$$

Entre los parámetros de evaluación clínica, se seleccionaron la sensibilidad y la especificidad, así (13):

$$
\begin{gathered}
\mathrm{S}=\frac{\mathrm{VP}}{\mathrm{VP}+\mathrm{FN}} \times 100 \% \\
\text { donde: } \begin{array}{c}
\mathrm{VP}: \text { verdaderos } \\
\text { positivos } \\
\mathrm{FN} \text { : falsos negativos }
\end{array} \\
\mathrm{E}=\frac{\mathrm{VN}}{\mathrm{VN}+\mathrm{FP}} \times 100 \% \\
\text { donde: } \begin{array}{l}
\text { VN: verdaderos negativos } \\
\mathrm{FP}: \text { falsos positivos }
\end{array}
\end{gathered}
$$

\section{Resultados y discusión}

Se realizó la predicción de secuencias antigénicas de la región del núcleo del HCV, empleando las escalas de propensión para sitios antigénicos (7) y el programa Microsoft Excel versión 7.0. Con base en esos resultados, se sintetizaron siete péptidos representativos de esta región, Core1, Core2, Core3, Core4, Core5, Core6 y Core7, de pesos moleculares teóricos de $3.479,47 \mathrm{kDa}$, $2.345,67 \mathrm{kDa}, 2.678,56 \mathrm{kDa}, 3.100,85 \mathrm{kDa}$, $2.987,67 \mathrm{kDa}, 2.806,98 \mathrm{kDa}$ y $2.986,43 \mathrm{kDa}$, respectivamente.

Los péptidos estaban comprendidos entre los aminoácidos 2-60 para Core1 (31 aminoácidos) y
Core2 (20 aminoácidos); entre los aminoácidos 40-90, los péptidos Core3 (26 aminoácidos), Core4 (20 aminoácidos), Core5 (27 aminoácidos) y Core6 (20 aminoácidos), y entre los aminoácidos 100130 el péptido Core7 (25 aminoácidos).

Se recubrieron las placas de $2 \mu \mathrm{g} / \mathrm{ml}$ con cada uno de los péptidos obtenidos y se analizó un panel de muestras procedentes del banco de sangre, previamente caracterizadas. Los resultados se muestran en la figura 1 . Los resultados de los valores de las muestras analizadas se muestran en el cuadro 1 (muestras positivas) y en el cuadro 2 (muestras negativas).

El péptido Core1, que está comprendido entre las secuencias I: a.a. del 5-26, 87\% y II: a.a. 13-32, $93 \%$ (15); entre las secuencias I: a.a. 1-18, $80 \%$; II: a.a. $11-28,84 \%$ y III: a.a. $21-38,72 \%$ (16) y en la secuencia I: a.a. 2-62, con $92 \%$ (17), posee una reactividad de $90,27 \%$ (65/72), que coincide con lo informado, lo cual demuestra que este péptido tiene gran antigenicidad para el grupo de muestras analizadas. Este péptido se caracterizó por espectrometría de masas MALDI-TOF. EI peso molecular obtenido fue de $3.474,73 \mathrm{kDa}$, que coincide con el valor teórico $(3.479,47 \mathrm{kDa})$.

El péptido Core2, comprendido en la secuencia III: a.a. $37-56,67 \%(15)$, mostró una reactividad de $86,11 \%$ (62/72), siendo superior a los valores informados, pero inferior a la mostrada por el péptido Core1.

Por su parte, Core3, comprendido entre las secuencias IV: a.a. 49-68, 67\% (15), III: a.a. 21$38,72 \%$ y IV: a.a. $51-68,68 \%$ (16), mostró una reactividad de $70,83 \%(51 / 72)$, valor que coincide con lo informado.

El péptido Core4, que se encuentra en la secuencia IV: a.a. 49-68, 67\% (15), posee una reactividad de $58,3 \%(42 / 72)$, valor también comprendido entre los informados.

El péptido Core5, que está comprendido entre las secuencias IV: a.a. $49-68,67 \%$ y V: a.a. $61-80$, $47 \%$ (15) y en la secuencia IV: a.a. $51-68,68 \%$ (16), aunque no se comporta como Core1, mostró también una buena reactividad $(62,5 \%)$ para las muestras de banco (45/72). 
Cuadro 1. Resultados de los péptidos de la región estructural frente a muestras positivas.

\begin{tabular}{|c|c|c|c|c|c|c|c|}
\hline Muestras & Core1 & Core2 & Core3 & Core4 & Core5 & Core6 & Core7 \\
\hline 5 & 6,42 & 4,43 & 4,12 & 3,38 & 2,71 & 3,67 & 1,04 \\
\hline 9 & 6,92 & 3,00 & 1,58 & 1,17 & 5,46 & 5,54 & 0,90 \\
\hline 51 & 3,17 & 2,58 & 2,25 & 2,33 & 2,21 & 2,88 & 0,54 \\
\hline 354 & 8,75 & 1,50 & 1,46 & 0,50 & 2,42 & 3,00 & 0,50 \\
\hline 358 & 5,71 & 1,71 & 1,79 & 1,08 & 1,20 & 1,01 & 0,93 \\
\hline 359 & 4,13 & 1,58 & 1,58 & 1,13 & 1,45 & 1,83 & 0,38 \\
\hline 364 & 5,96 & 1,58 & 1,38 & 0,29 & 0,46 & 0,75 & 0,58 \\
\hline 370 & 8,67 & 5,63 & 4,00 & 0,25 & 0,54 & 1,33 & 0,42 \\
\hline 390 & 5,54 & 3,88 & 4,58 & 1,13 & 1,20 & 1,18 & 0,59 \\
\hline 3901 & 5,63 & 4,88 & 4,96 & 1,05 & 1,20 & 1,54 & 0,63 \\
\hline 253 & 1,88 & 2,96 & 3,13 & 2,17 & 1,40 & 1,12 & 0,17 \\
\hline 304 & 2,83 & 1,92 & 1,79 & 2,88 & 1,83 & 1,92 & 0,33 \\
\hline 474 & 1,79 & 1,67 & 1,13 & 1,25 & 0,50 & 1,02 & 0,60 \\
\hline 511 & 5,79 & 3,79 & 2,00 & 1,88 & 0,38 & 0,58 & 0,33 \\
\hline 511 & 5,42 & 3,46 & 1,79 & 1,79 & 0,50 & 0,50 & 0,46 \\
\hline 518 & 1,13 & 1,21 & 0,88 & 0,80 & 0,71 & 0,71 & 0,58 \\
\hline 578 & 8,79 & 6,79 & 3,75 & 1,04 & 2,23 & 0,34 & 0,13 \\
\hline 584 & 1,54 & 1,50 & 0,96 & 0,42 & 0,18 & 0,34 & 0,26 \\
\hline 643 & 4,33 & 2,08 & 1,21 & 0,50 & 0,71 & 1,71 & 0,75 \\
\hline 676 & 1,29 & 1,50 & 2,08 & 1,63 & 5,46 & 4,92 & 5,75 \\
\hline 3423 & 1,38 & 1,96 & 0,96 & 1,13 & 0,42 & 1,25 & 0,67 \\
\hline MM6 & 1,62 & 2,94 & 0,46 & 0,25 & 1,59 & 0,75 & 0,93 \\
\hline MM7 & 1,20 & 1,68 & 0,22 & 0,32 & 1,15 & 0,77 & 0,75 \\
\hline VOL9 & 1,46 & 1,23 & 6,02 & 4,85 & 4,50 & 0,52 & 0,43 \\
\hline J06 & 1,25 & 3,12 & 0,53 & 0,38 & 5,47 & 0,15 & 0,23 \\
\hline J07 & 2,36 & 1,09 & 4,92 & 1,33 & 4,69 & 0,15 & 0,12 \\
\hline $\mathrm{JH} 11$ & 0,49 & 0,70 & 0,26 & 0,43 & 0,44 & 0,25 & 0,22 \\
\hline 204-5 & 0,27 & 0,68 & 0,15 & 0,32 & 0,73 & 3,36 & 3,28 \\
\hline $204-18$ & 2,07 & 2,39 & 1,77 & 0,59 & 0,42 & 0,49 & 0,41 \\
\hline 204-19 & 1,24 & 2,11 & 1,53 & 1,03 & 1,30 & 0,87 & 1,11 \\
\hline $103-8$ & 1,65 & 1,74 & 0,92 & 0,54 & 0,20 & 0,38 & 0,51 \\
\hline 4 & 1,80 & 1,66 & 0,40 & 0,47 & 0,39 & 0,70 & 5,20 \\
\hline 111 & 1,35 & 1,91 & 2,17 & 0,86 & 0,54 & 0,43 & 0,42 \\
\hline P07 & 1,14 & 3,00 & 1,77 & 0,84 & 1,50 & 0,99 & 0,94 \\
\hline $902-11$ & 1,51 & 2,97 & 1,90 & 1,01 & 1,10 & 0,73 & 0,52 \\
\hline 26 & 5,80 & 4,870 & 3,670 & 2,500 & 1,45 & 0,86 & 1,13 \\
\hline 80 & 3,15 & 2,600 & 1,780 & 1,150 & 1,39 & 0,80 & 0,75 \\
\hline 92 & 1,50 & 1,600 & 1,400 & 1,200 & 1,00 & 0,47 & 0,75 \\
\hline 149 & 5,57 & 2,11 & 1,760 & 1,340 & 2,72 & 1,55 & 0,297 \\
\hline 506 & 1,48 & 2,98 & 1,430 & 0,800 & 0,75 & 0,23 & 0,163 \\
\hline 1069 & 0,63 & 0,42 & 0,093 & 0,186 & 0,65 & 0,55 & 0,203 \\
\hline 2622 & 5,32 & 5,45 & 4,460 & 3,230 & 2,97 & 1,82 & 1,120 \\
\hline 2640 & 1,15 & 1,10 & 0,417 & 0,513 & 0,55 & 0,20 & 0,250 \\
\hline 2809 & 1,30 & 1,200 & 0,587 & 0,623 & 0,38 & 0,47 & 0,25 \\
\hline 2869 & 1,42 & 1,240 & 1,200 & 1,38 & 1,23 & 1,55 & 0,41 \\
\hline 3170 & 5,56 & 3,697 & 3,193 & 3,674 & 4,85 & 3,93 & 0,577 \\
\hline 4062 & 3,19 & 5,13 & 4,530 & 2,58 & 1,80 & 4,49 & 0,560 \\
\hline 4077 & 5,74 & 4,34 & 4,230 & 3,470 & 2,13 & 0,46 & 0,617 \\
\hline 4182 & 5,20 & 4,45 & 3,450 & 2,980 & 1,71 & 0,50 & 0,537 \\
\hline 4229 & 5,90 & 2,04 & 3,270 & 2,700 & 1,88 & 1,23 & 0,800 \\
\hline 6634 & 1,20 & 1,71 & 1,130 & 1,170 & 1,20 & 0,93 & 0,82 \\
\hline 7049 & 5,43 & 5,430 & 3,380 & 2,560 & 1,39 & 0,49 & 0,36 \\
\hline 7049 & 5,20 & 4,970 & 3,120 & 1,870 & 1,40 & 0,45 & 0,39 \\
\hline 7350 & 5,35 & 5,250 & 3,450 & 2,230 & 1,29 & 1,11 & 1,45 \\
\hline 7730 & 5,18 & 5,070 & 3,290 & 2,100 & 3,51 & 2,20 & 0,30 \\
\hline 8840 & 3,00 & 2,890 & 1,980 & 1,500 & 1,30 & 0,68 & 0,84 \\
\hline 9602 & 1,24 & 1,120 & 1,030 & 1,100 & 1,38 & 1,20 & 0,45 \\
\hline
\end{tabular}


Cuadro 1. Resultados de los péptidos de la región estructural frente a muestras positivas (continuación).

\begin{tabular}{rlllllll}
\hline Muestras & Core1 & Core2 & Core3 & Core4 & Core5 & Core6 & Core7 \\
\hline E1662 & 4,80 & 4,360 & 3,890 & 2,500 & 3,71 & 1,05 & 3,20 \\
E6627 & 5,54 & 4,470 & 4,030 & 2,370 & 2,49 & 1,55 & 0,87 \\
P07 & 6,33 & 5,82 & 2,63 & 3,38 & 1,04 & 2,75 & 0,87 \\
13 & 6,67 & 5,92 & 3,63 & 5,33 & 4,33 & 6,17 & 0,50 \\
111 & 6,00 & 5,63 & 1,33 & 2,63 & 2,34 & 1,83 & 0,63 \\
4 & 5,54 & 4,75 & 1,42 & 3,04 & 2,50 & 2,83 & 0,88 \\
43 & 2,50 & 1,50 & 0,29 & 0,79 & 0,38 & 0,63 & 0,46 \\
358 PM & 1,04 & 0,89 & 0,75 & 0,597 & 0,58 & 1,00 & 0,34 \\
9 & 0,46 & 0,02 & 0,46 & 0,432 & 0,42 & 0,42 & 0,71 \\
$204-19$ & 0,54 & 0,88 & 0,58 & 0,6 & 0,63 & 0,50 & 0,54 \\
$103-3$ & 0,63 & 0,71 & 0,17 & 0,42 & 0,17 & 0,33 & 0,21 \\
$103-6$ & 0,58 & 0,17 & 0,75 & 0,68 & 0,33 & 0,50 & 0,54 \\
1685 & 1,00 & 0,97 & 0,67 & 0,45 & 0,75 & 0,58 & 0,75 \\
358 & 6,17 & 5,58 & 5,17 & 4,50 & 5,75 & 4,83 & 4,92 \\
305 & 1,75 & 0,79 & 0,67 & 0,38 & 0,67 & 0,50 & 0,63 \\
\hline
\end{tabular}
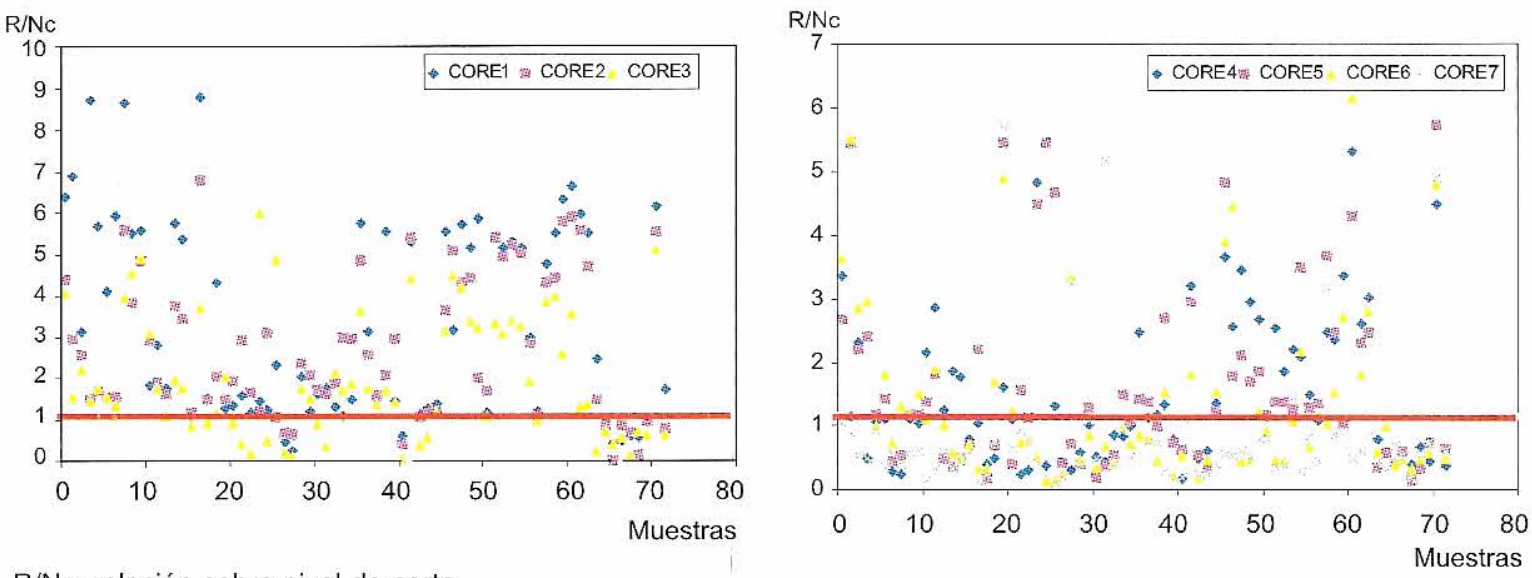

R/Nc: relación sobre nivel de corte

Muestras: número de muestras analizadas

Figura 1. Resultados de los péptidos de la región del núcleo del HCV con muestras positivas.

El péptido Core6, comprendido en la secuencia IV: a.a. $51-68,68 \%(16)$, posee una reactividad de $48,613 \%$ (35/72), valor muy similar a lo informado.

El péptido Core7 fue capaz de reconocer solamente un $13,8 \%$ (10/72), por lo que pudimos concluir que no es antigénico para el grupo de muestras analizadas. Esta secuencia coincide con la V: a.a.101-118, 72\% (16); sin embargo, no se obtienen los resultados mencionados.

Exceptuando el péptido Core7, la reactividad de los péptidos obtenidos por nosotros osciló entre 48 y $96 \%$, lo que coincide con lo informado por
Deleys y colaboradores, 1992 (47-93\%); Sallberg y colaboradores, 1992 (68-84\%); Nakagiri e Ichihara, 1995 (92\%), e Ishida y colaboradores, $1993(97,5 \%)$.

El no reconocimiento de las muestras reportadas como positivas por parte de los péptidos se puede deber a que los anticuerpos de las muestras no reconozcan ninguno de los determinantes antigénicos presentes en los péptidos; que los títulos de anticuerpos no sean lo suficientemente altos en correspondencia con la concentración del antígeno en fase sólida, o que la disposición espacial de los determinantes antigénicos, al 
Cuadro 2. Resultados de los péptidos de la región estructural frente a muestras negativas.

\begin{tabular}{|c|c|c|c|c|c|c|c|}
\hline Muestras & Core1 & Core2 & Core3 & Core 4 & Core5 & Core6 & Core7 \\
\hline 2 & 0,043 & 0,027 & 0,007 & 0,047 & 0,060 & 0,170 & 0,290 \\
\hline 5 & 0,200 & 0,003 & 0,003 & 0,067 & 0,070 & 0,140 & 0,187 \\
\hline 16 & 0,173 & 0,053 & 0,063 & 0,100 & 0,527 & 0,300 & 0,119 \\
\hline 20 & 0,110 & 0,003 & 0,003 & 0,043 & 0,577 & 0,100 & 0,187 \\
\hline 110 & 0,287 & 0,260 & 0,003 & 0,417 & 0,363 & 0,103 & 0,180 \\
\hline 135 & 0,587 & 0,050 & 0,051 & 0,653 & 0,574 & 0,693 & 0,653 \\
\hline 208 & 0,057 & 0,003 & 0,003 & 0,297 & 0,280 & 0,070 & 0,073 \\
\hline 214 & 0,327 & 0,190 & 0,130 & 0,283 & 0,053 & 0,413 & 0,450 \\
\hline 228 & 0,290 & 0,207 & 0,003 & 0,407 & 0,300 & 0,173 & 0,273 \\
\hline 272 & 0,093 & 0,003 & 0,003 & 0,287 & 0,270 & 0,097 & 0,203 \\
\hline 274 & 0,087 & 0,003 & 0,003 & 0,400 & 0,587 & 0,017 & 0,063 \\
\hline 275 & 0,060 & 0,003 & 0,003 & 0,437 & 0,637 & 0,170 & 0,193 \\
\hline 291 & 0,187 & 0,003 & 0,003 & 0,337 & 0,497 & 0,310 & 0,187 \\
\hline 311 & 0,103 & 0,003 & 0,003 & 0,407 & 0,720 & 0,083 & 0,117 \\
\hline 330 & 0,257 & 0,160 & 0,063 & 0,277 & 0,563 & 0,220 & 0,223 \\
\hline 342 & 0,067 & 0,003 & 0,003 & 0,210 & 0,343 & 0,117 & 0,077 \\
\hline 359 & 0,020 & 0,003 & 0,003 & 0,003 & 0,213 & 0,063 & 0,117 \\
\hline 372 & 0,140 & 0,003 & 0,003 & 0,190 & 0,330 & 0,197 & 0,250 \\
\hline 376 & 0,227 & 0,003 & 0,003 & 0,007 & 0,120 & 0,210 & 0,327 \\
\hline 379 & 0,120 & 0,090 & 0,003 & 0,003 & 0,057 & 0,227 & 0,197 \\
\hline 380 & 0,113 & 0,003 & 0,003 & 0,023 & 0,103 & 0,297 & 0,253 \\
\hline 384 & 0,110 & 0,003 & 0,003 & 0,003 & 0,003 & 0,123 & 0,187 \\
\hline 426 & 0,133 & 0,033 & 0,003 & 0,070 & 0,037 & 0,137 & 0,197 \\
\hline 427 & 0,150 & 0,003 & 0,003 & 0,023 & 0,090 & 0,093 & 0,130 \\
\hline 429 & 0,147 & 0,003 & 0,003 & 0,073 & 0,123 & 0,193 & 0,240 \\
\hline 432 & 0,117 & 0,017 & 0,003 & 0,080 & 0,020 & 0,117 & 0,067 \\
\hline 550 & 0,700 & 0,703 & 0,693 & 0,003 & 0,013 & 0,663 & 0,630 \\
\hline 545 & 0,033 & 0,050 & 0,470 & 0,003 & 0,600 & 0,170 & 0,200 \\
\hline 665 & 0,517 & 0,240 & 0,183 & 0,003 & 0,003 & 0,453 & 0,653 \\
\hline 680 & 0,540 & 0,220 & 0,190 & 0,003 & 0,003 & 0,413 & 0,530 \\
\hline 1088 & 0,420 & 0,380 & 0,280 & 0,027 & 0,030 & 0,397 & 0,450 \\
\hline 2011 & 0,257 & 0,197 & 0,187 & 0,003 & 0,100 & 0,293 & 0,537 \\
\hline 2778 & 0,780 & 0,657 & 0,680 & 0,057 & 0,097 & 0,807 & 0,700 \\
\hline 2805 & 0,563 & 0,493 & 0,363 & 0,103 & 0,137 & 0,340 & 0,243 \\
\hline 10786 & 0,733 & 0,403 & 0,517 & 0,020 & 0,053 & 0,503 & 0,550 \\
\hline 10902 & 0,193 & 0,270 & 0,260 & 0,007 & 0,087 & 0,687 & 0,340 \\
\hline 11111 & 0,413 & 0,410 & 0,427 & 0,003 & 0,037 & 0,637 & 0,350 \\
\hline $7 \mathrm{~m}^{1}$ & 0,097 & 0,003 & 0,003 & 0,033 & 0,057 & 0,227 & 0,303 \\
\hline $7 \mathrm{~m} 2$ & 0,020 & 0,003 & 0,003 & 0,003 & 0,047 & 0,143 & 0,160 \\
\hline $8 m$ & 0,220 & 0,217 & 0,077 & 0,003 & 0,063 & 0,277 & 0,250 \\
\hline $9 m$ & 0,633 & 0,300 & 0,050 & 0,187 & 0,137 & 0,407 & 0,337 \\
\hline $\mathrm{Dr}$ & 0,143 & 0,077 & 0,210 & 0,003 & 0,120 & 0,563 & 0,407 \\
\hline
\end{tabular}

unirse a la fase sólida, no sea la adecuada y queden solapados.

La especifidad de todos los péptidos obtenidos al analizar 42 muestras informadas como negativas fue de $100 \%$, resultados que se muestran en la figura 2.

Los resultados de especificidad y sensibilidad de cada uno de los péptidos de la región estructural se muestran en el cuadro 3.
Cuadro 3. Resultados de la especificidad y sensibilidad de los péptidos de la región estructural.

\begin{tabular}{|c|c|c|c|c|}
\hline Péptidos & Muestras & $\begin{array}{c}\text { Sensibilidad } \\
(\%)\end{array}$ & Muestras & $\begin{array}{c}\text { Especificidad } \\
(\%)\end{array}$ \\
\hline Core1 & $165 / 72$ & 90,27 & $42 / 42$ & 100 \\
\hline Core2 & $62 / 72$ & 86,11 & $42 / 42$ & 100 \\
\hline Core3 & $51 / 72$ & 70,83 & $42 / 42$ & 100 \\
\hline Core4 & $42 / 72$ & 58,30 & $42 / 42$ & 100 \\
\hline Core5 & $45 / 72$ & 62,50 & $42 / 42$ & 100 \\
\hline Core6 & $35 / 72$ & 48,61 & $42 / 42$ & 100 \\
\hline Core7 & $10 / 72$ & 13,80 & $42 / 42$ & 100 \\
\hline
\end{tabular}




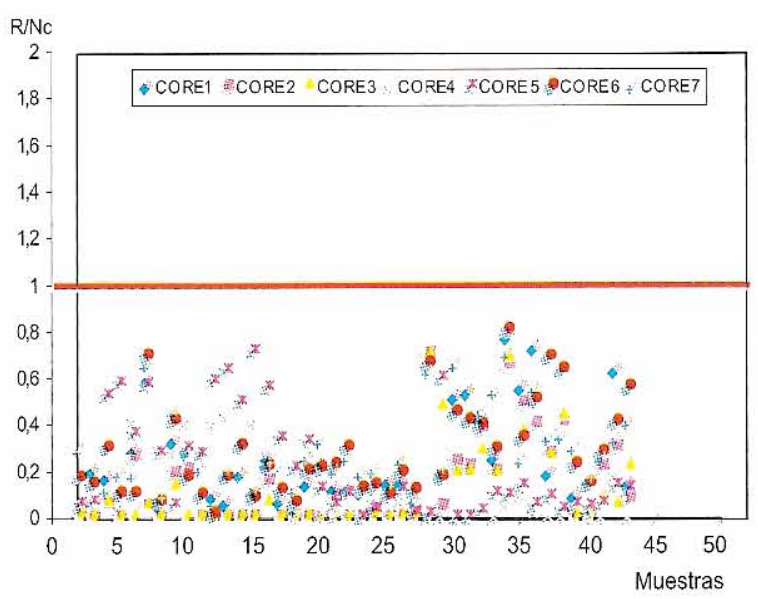

$\mathrm{R} / \mathrm{Nc}$ : relación sobre nivel de corte

Muestras: número de muestras analizadas

Figura 2. Resultados de los péptidos de la región del núcleo del HCV con muestras negativas.

Como se puede observar, los péptidos cercanos a la región amino terminal, que es la más antigénica, son los que presentan la mayor reactividad; a medida que nos alejamos de esta zona hacia la región carboxilo-terminal, la reactividad va disminuyendo (3-5).

\section{Agradecimientos}

Al Departamento de Análisis Espectral del Instituto de Inmunología de Colombia por la colaboración prestada en la caracterización por espectrometría de masas de los péptidos sintetizados.

\section{Referencias}

1. Gómez I. Obtención y evaluación de péptidos sintéticos inmunodominantes de la región estructural y no estructural del virus de la hepatitis $\mathrm{C}$ (tesis). Universidad de La Habana, La Habana; 1999.

2. Lunel F, Pawlotsky JM. Hepatitis C virus. Virological diagnosis. Pathol Biol 1995;43:681-90.

3. Bonino F, Baldi M, Brunetto MR. Hepatitis C virus infection. In: Crivelli $O$, editor. Progress in hepatitis research: hepatitis $B$ virus (HBV), hepatitis $C$ virus (HCV), hepatitis delta virus (HDV). Sorin Biomedica 1994;49-61.

4. Cuthbert JA. Hepatitis C: progress and problems. Clin Microbiol Rev 1994;7:505-32.

5. Robinson JW, Rosas M, Guzmán F, Patarroyo ME, Moreno A. Comparison of prevalence of anti-hepatitis C virus antibodies in differing South American populations. J Med Virol 1996;50:188-92.

6. Yoshihara N. ELISA for diagnosis of infections by viruses. Nippon Rinsho 1995;53:2277-82.

7. Chou PY, Fasman GD. Prediction of protein conformation. Biochemistry 1974;13:222-45.

8. Merrifield RB. Peptide synthesis. I. The synthesis of a tetropeptide. J Am Chem Soc 1963;85:2149.

9. Houghten RA. Simultaneous multiple peptide synthesis: the rapid preparation of large numbers of discretes peptides for biological, immunological and methodological studies. Biotechniques 1986;4:522.

10. Stone KL, LoPresti MB, Myron J, DeAngelis R, Williams KR. Enzymatic digestion of proteins and HPLC peptide isolation. In: A practical guide to protein and peptide purification for microsequencing. London: Academic Press, Inc.; 1989. p.31-47.

11. Holle A, Mayer FJ. Matrix-assisted laser desorption on the REFLEX ${ }^{T M}$ time of flight mass spectrometry system. Mass Spectrometry 1993;18-20.

12. Boudet F, These J, Zouali M. UV-treated polystyrene microtitre plates for use in an ELISA to measure antibodies against synthetic peptides. J Immunol Methods 1991; 142:73-82.

13. Gómez I, Cazanave J, Solís RL, Machado C, Bécquer D, Fernández JL. A new UMELISA format for the quantification of maternal serum alpha-fetoprotein. Biotecnología Aplicada 1996;13:109.

14. Broughton PMG, Bergonzi C, Lindstedt G, Loeber JG, Malan PG. Guidelines for the evaluation of diagnostic kits. General principles and outline procedures for the evaluation of kits for qualitative tests. Part 2. Paris: European Committee for Clinical Laboratory Standards; 1987

15. Deleys RJ, Pollet D, Maertens G, Van Heuverswyn H, inventors; Innogenetics N. V., assignee. Synthetic antigens for the detection of antibodies to hepatitis $\mathrm{C}$ virus. US Patent No. 0489968 A1. 1992 March 16.

16. Sallberg M, Ruden U, Wahren B, Magnius LO. Immunodominant regions within the hepatitis $\mathrm{C}$ virus core and putative matrix proteins. J Clin Microbiol 1992;30: 1989-94.

17. Nakagiri I, Ichihara K. ELISA for anti-HCV antibody employing a shorter synthetic core region peptide. J Virol Methods 1995;52:195-207.

18. Ishida C, Matsumoto K, Fukada K, Matsushita K, Shiraki H, Maeda Y. Detection of antibodies to hepatitis $\mathrm{C}$ virus (HCV) structural proteins in anti-HCV-positive sera by an enzyme-linked immunosorbent assay using synthetic peptides as antigens. J Clin Microbiol 1993;31: 936-40. 